\title{
Birth weight is not associated with risk of fracture. Results from two Swedish cohort studies
}

Liisa Byberg, ${ }^{1}$ Karl Michaëlsson, ${ }^{1}$ Anna Goodman, ${ }^{2}$ Björn Zethelius, ${ }^{3}$ Ilona Koupil ${ }^{2,4}$

1. Department of Surgical Sciences, Orthopaedics, Uppsala University, Uppsala, Sweden (LB, KM),

2. London School of Hygiene and Tropical Medicine, London, UK (AG),

3. Department of Public Health and Caring Sciences, Geriatrics, Uppsala University, Uppsala, Sweden and Medical Products Agency, Uppsala, Sweden

4. Centre for Health Equity Studies (CHESS), Stockholm University and Karolinska Institutet, Stockholm, Sweden

Corresponding author: Liisa Byberg, UCR/Scheele, Uppsala Science Park, SE-75185 Uppsala, Sweden (liisa.byberg@ surgsci.uu.se).

Note: this is a personal version, created by Anna Goodman, of the text of the accepted journal article. It reflects all changes made in the peer review process, but does not incorporate any minor modifications made at the proof stage. The complete citation for the final journal article is:

- Byberg, L., K. Michaëlsson, A. Goodman, B. Zethelius and I. Koupil (2014).

"Birth weight is not associated with risk of fracture. Results from two cohorts." Journal of Bone and Mineral Research 29(10): 2152-2160

- DOI: $10.1002 / j b m r .2246$

Copyright (C) and Moral Rights for this paper are retained by the individual authors and/or other copyright owners 


\begin{abstract}
$\underline{\text { Abstract }}$
Development and growth in utero has been suggested to influence bone health. However, the relationship with risk of fracture in old age is largely unknown. Using Cox proportional hazards regression, we studied the association between birth weight and fractures at ages 50-94 among 10,893 men and women (48\% women) from the Uppsala Birth Cohort Study (UBCoS, born 1915-29) and 1,334 men from the Uppsala Longitudinal Study of Adult Men (ULSAM, born 1920-24). Measured birth weight was collected from hospital or midwives' records and fractures from the Swedish National Patient Register. We observed 2,796 fractures (717 of these were hip fractures) in UBCoS and 335 fractures (102 hip fractures) in ULSAM. In UBCoS, the hazard ratio (HR) per $1 \mathrm{~kg}$ increase in birth weight, adjusted for sex and socioeconomic status at birth, was 1.01 (95\% confidence interval [CI], 0.94-1.09) for any fracture and 1.06 (95\% CI, 0.91-1.23) for hip fracture. Estimates in ULSAM were similar. We did not observe a differential association of birth weight with fractures occurring before age 70 or after age 70 years. Neither birth weight standardized for gestational age nor gestational duration was associated with fracture rate. In linear regression, birth weight was not associated with bone mineral density among 303 82-year-old men in ULSAM but showed positive associations with total body bone mineral content ( $\beta$ per kg increase in birth weight, adjusted for social class and age, 133; 95\% CI, 30-227). This association was attenuated after further adjustment for body mass index and height ( $\beta, 41 ; 95 \% \mathrm{CI},-43$ to 126$)$. We conclude that birth weight is associated with bone mineral content but this association does not translate into an association with risk of fracture in men and women aged 50-94 years.
\end{abstract}

Key Words: Fracture, birth weight, cohort study, bone mineral density, bone mineral content. 


\section{$\underline{\text { Introduction }}$}

Osteoporosis has been suggested to be partly programmed in early life. ${ }^{(1)}$ Several studies indicate that size at birth and/or growth during the first years of life are associated with bone mineral content although less so with bone mineral density. ${ }^{(2-6)}$ The association seems to be largely dependent on body size at the time of the bone measurement, both in children $^{(7)}$ and adolescents, ${ }^{(8)}$ and in adult twins. ${ }^{(5)}$ Nevertheless, the tracking of bone mass throughout life is suggested to influence peak bone mass and thereby fracture risk. ${ }^{(9)}$ Only a few studies, however, investigate the association of early growth with later fractures, the conceivable clinical consequence of osteoporosis. In two large Finnish cohorts, birth weight was not associated with hip fracture risk $^{(10,11)}$ but the cohorts were only followed until a maximum age of 71 years and only a modest number of fractures were observed ( $\mathrm{N}=112$ in one and $\mathrm{N}=49$ in the other). A few other studies, without conclusive results, have investigated birth weight and length in relation with fracture risk in prepubertal children. ${ }^{(12,13)}$ Although studies on birth weight and fractures are scarce and inconclusive, other early life factors, including postnatal growth and circumstances, may be of additional importance. A low rate of childhood growth ${ }^{(10)}$ and thinness in childhood $^{(11)}$ were associated with hip fracture risk in the Finnish cohort studies. Whether these associations are a consequence of childhood lifestyle, genetic background or intrauterine programming is at present unclear since thinness and low weight gain also in adulthood are strongly associated with future hip fracture risk. ${ }^{(14)}$ Height, weight and bone mineral density also have a high heritability. ${ }^{(15)}$

To investigate further the association between birth weight and fracture risk in old age, we identified fractures of any type and fracture of the hip occurring between ages 50 and 94 years in two cohorts with register information on both size at birth and fracture incidence. Birth weight ${ }^{(16)}$ and fracture risk ${ }^{(17-19)}$ (including low bone mineral density ${ }^{(20)}$ ) are related with socioeconomic position, which constitutes an important potential confounder that we were able to take into account. Additionally, we studied the association of birth weight with bone mineral density (BMD) and bone mineral content (BMC) in a subsample of one of the cohorts. The influence of adult height and weight on the potential associations was examined. To make our results comparable with previous studies on hip fracture and because lifestyle factors seem more important than do heritable factors after the age of $70,{ }^{(21)}$ we performed analyses stratified by age.

\section{$\underline{\text { Subjects and methods }}$}

This study is based on two cohorts, the Uppsala Birth Cohort Study (UBCoS) and the Uppsala Longitudinal Study of Adult Men (ULSAM), as outlined in Figure 1. 
Figure 1. Flowchart of Uppsala Birth Cohort Study (UBCoS) and Uppsala Longitudinal Study of Adult Men (ULSAM). DXA: dual x-ray absorptiometry

UBCOS

14,192 children born at Uppsala University Hospital in 1915-1929

11,180 men and women traced, alive and resident in Sweden at age 50

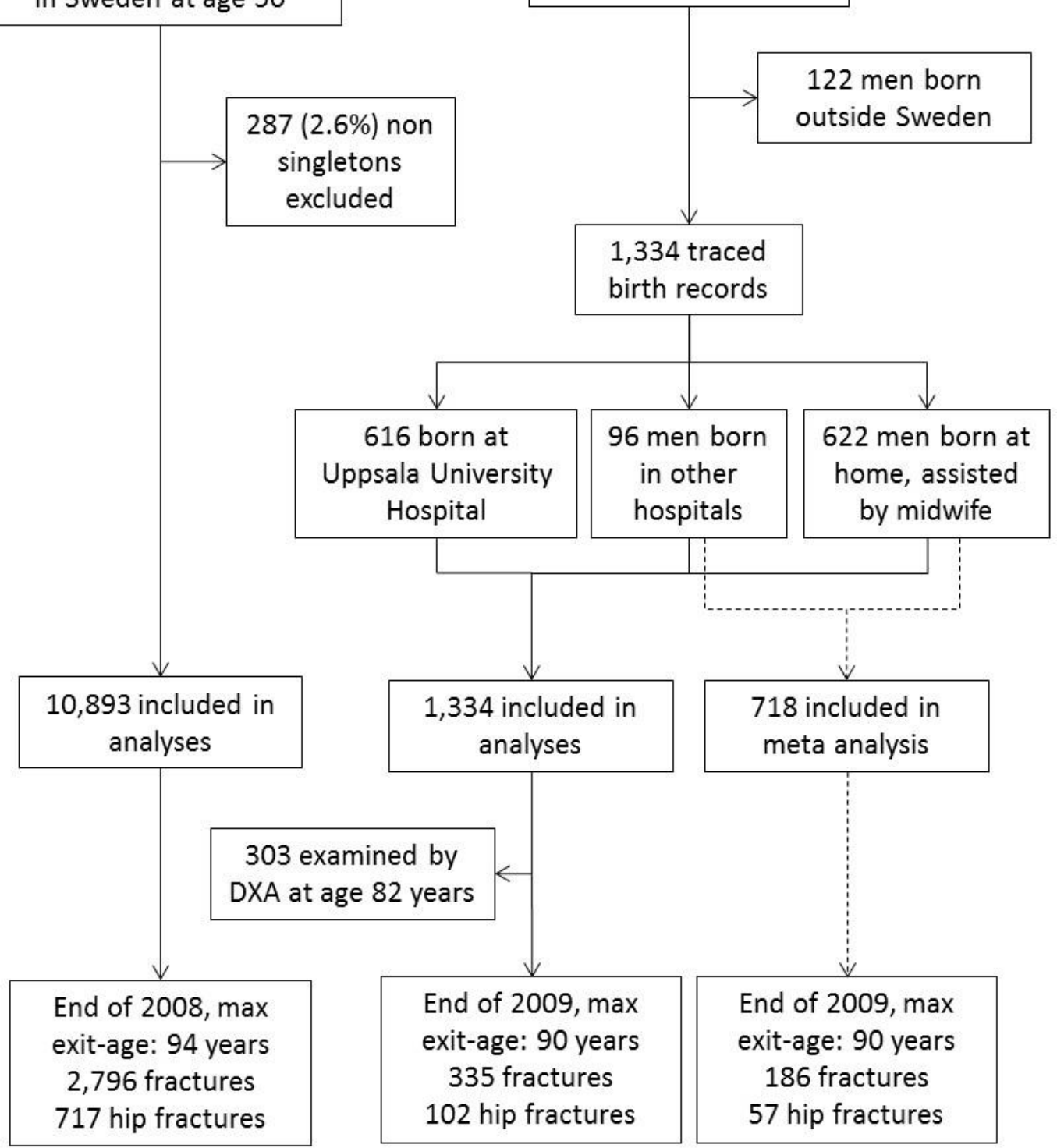

\section{ULSAM}

\section{2,841 men born 1920-24 and} living in Uppsala County

1 Jan 1970 invited

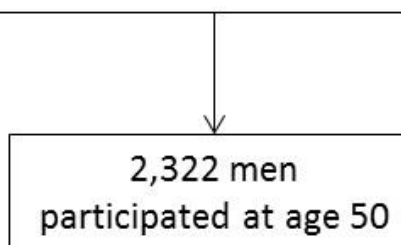


UBCoS is a register study of all births at Uppsala University Hospital between 1915 and 1929 and has been described in detail previously. ${ }^{(22)}$ In the present analysis, 13,811 of the 14,192 live births recorded were traced in population registers (98\%), of which 11,180 remained alive and resident in Sweden until the age of 50 years. Of these, we included 10,893 singleton men and women (48\% women) in the present analysis. We excluded multiple births $(\mathrm{N}=287 ; 2.6 \%)$ since twins and triplets tend to be both smaller and lighter at birth. The cohort was followed via official Swedish registers until 31 December 2008, using their unique personal identification numbers.

ULSAM is a population-based clinical investigations cohort to which all men born 1920-24 and living in Uppsala in January 1970 were invited. The study and the clinical investigations have been described in detail previously. ${ }^{(23)}$ Briefly, 2,841 men were invited and 2,322 men participated when they were approximately 50 years old. We traced the birth records of $1,334(57 \%)$ of these men. ${ }^{(24)}$ Of the men whose birth records were traced, $616(46 \%)$ were born at the Uppsala University Hospital and are thus also part of the UBCoS cohort and another 96 men (7\%) were born in other hospitals. The remaining 622 men $(47 \%)$ were born at home and the information was retrieved from midwives' records. The cohort was followed via official Swedish registers until 31 December 2009. We compared men with and without birth weight information to assess the representativeness of the included men. Height, weight and body mass index (BMI) did not differ between the groups whereas being current smoking habits (52 vs. 49\%) and belonging to the lowest social class (49 vs. $41 \%$ ) was more common among those men with information on birth weight.

The studies were approved by the regional Ethics committees in Stockholm (UBCoS) and in Uppsala (ULSAM). ULSAM participants gave their informed consent.

\section{Exposures}

Our main exposure was birth weight measured with a scale. We used birth weight as a continuous variable and categorized into $<2.5 \mathrm{~kg}, 2.5-2.9 \mathrm{~kg}, 3.0-3.4 \mathrm{~kg}, 3.5-3.9 \mathrm{~kg}$, and $\geq 4.0 \mathrm{~kg}$. In UBCoS, we also studied whether gestational age (in weeks), birth weight standardized to gestational age, and birth length (in $\mathrm{cm}$ ) were associated with fracture risk. This information was retrieved from the birth records. Hospitals recorded birth weight to the nearest $10^{\text {th }}$ or $5^{\text {th }}$ gram. The precision of birth weight measurements in midwives' archives is less known but rounding to the nearest half or whole kg was not uncommon. ${ }^{(25)}$ We further grouped birth length, gestational age (weeks), and standardized birth weight into quintiles based on centiles calculated from the full cohort.

\section{Outcomes}

Our outcomes of interest were fractures of the hip (International Classification of Disease (ICD)-10 codes S720, S721, or S722) and any type of fracture from the neck down (ICD10 codes S12, S22, S32, S42, S52, S62, S72, S82, or S92) after the age of 50 years (UBCoS) or after study entry at approximately age 50 (ULSAM). Any type of non-hip fracture, thus excluding hip fractures (as defined above), was used as outcome in 
sensitivity analysis. The corresponding ICD codes for earlier versions were used when needed, and fractures occurring before the age of 50 were recorded as previous fractures. Outcomes were identified from the National Patient Register and additional fractures were obtained by retrieving information from local fracture registers for ULSAM. ${ }^{(26)}$ The National Patient Registry is valid for identification of fractures ${ }^{(27-30)}$ and was initiated in 1964. Uppsala County Council contributed to the registry from the start. In 1972, the registry covered $83 \%$ of the Swedish population and covers all inpatient care for the whole country since 1987.

In 2003-2005, during the fifth examination cycle of the ULSAM cohort 303 approximately 82-year-old men with information on birth weight participated in a dual xray absorptiometry (DXA) (Lunar Prodigy, Lunar Corp. Madison, WI, USA) examination for determination of total body, total hip, and lumbar spine bone mineral density (BMD, $\mathrm{g} / \mathrm{cm}^{2}$ ) and content (BMC, g), as described previously. ${ }^{(31)} \mathrm{BMD}$ and BMC at these sites were therefore examined as secondary outcomes.

\section{UBCoS covariates}

The hospital records included information on birth weight and length, gestational age, mother's age and social class. Social class at birth was based on father's occupation recorded in the birth record and if this was missing, mother's occupation was used. Categories used were non-manual worker, self-employed/farmer, manual worker, and other. Birth weight standardized to gestational age was calculated as described previously. ${ }^{(32)}$ Information on height at conscription (at approximately age 18 years) was retrieved from The Military Archives of Sweden (Krigsarkivet) ${ }^{(33)}$ in a subgroup of 1,241 singleton men in the UBCoS.

\section{ULSAM covariates}

Height and weight at age 50 years was measured without shoes and in light underclothing to the nearest $\mathrm{cm}$ and $\mathrm{kg}$, respectively. BMI was calculated as weight (in $\mathrm{kg}$ ) divided by height (in meters) squared. Information on smoking habits was retrieved by interview and classified as current, former and never. Social class was categorized as high (employers/entrepreneurs, higher ranked white collar workers), middle (small business employers, supervisors, white collar workers, farmers), and low (lower ranked workers, unemployed), according to the at that time (1970) current classification. ${ }^{(34)} \mathrm{BMI}$ and height at time of the DXA measurement were included as covariates in analyses of BMD and BMC.

\section{Comorbidity}

Diagnosis codes were collated from the national patient registry (ICD codes 7-10) to calculate number of Charlson comorbidities. ${ }^{(35,36)}$ The Charlson comorbidity index predicts the 10 year mortality for a patient who may have a range of comorbid conditions (up to 17 diseases). Comorbidity was defined as one or more Charlson's comorbidity before age 50 (in UBCoS) or before baseline (in ULSAM). 


\section{Statistical analyses}

We used Cox's proportional hazards regression for assessment of the association between birth weight and fracture risk after age 50 years. Time at risk was calculated from date of the $50^{\text {th }}$ birthday (in UBCoS) or the examination date at approximate age 50 (in ULSAM) until the date of fracture, date of emigration, date of death, or until end of follow-up (31 December 2008 for UBCoS and 31 December 2009 for ULSAM). The proportional hazards assumption was tested using Schoenfeld's residuals and visual judgment of log$\log$ plots. No violations of the assumptions were observed.

We assessed the potential interactions between sex and birth weight using likelihood ratio tests. Based on these results, and to facilitate comparisons between UBCoS and ULSAM (and also other studies), we present the results of the UBCoS separately for men and women. Potential non-linearity was examined by introducing a square term of the continuous exposure variable in our model, and by assessing models with the categorized variables.

Covariates introduced in our adjusted models were selected based on the directed acyclic graph (DAG) method ${ }^{(37)}$ (Supplemental Figure 1a and 1b). In a first adjusted model, our main model, social class at birth was included in the estimation of the total effect of birth weight on fracture risk in UBCoS. In ULSAM we replaced social class at birth with that in adulthood and added age at examination. In a second model in UBCoS, we included mother's parity and the child's gestational age. In a third model we additionally included the comorbidity index in UBCoS; and height and BMI, smoking habits, and the comorbidity index in ULSAM. For associations with hip fracture, the third model also included previous non-hip fracture. In a subgroup of UBCoS men, we also included information on adult height in a model together with social class at birth.

To get a pooled estimate of the association between birth weight and hip fracture based on our cohorts, we performed fixed effects meta-analysis using the two parameter syntax of metan in Stata. ${ }^{(38)}$ The associations of birth weight with BMD and BMC were assessed using linear regression and adjusted means (adjusted for age at DXA and adult social class) in each birth weight category were calculated.

We also conducted sensitivity analyses of our results. Firstly, we assessed whether the association between birth weight and fracture risk differed for fractures occurring between ages 50 and 70 years, and for fractures occurring at age 70 years or above. Secondly, we assessed whether mortality would introduce problems by competing risk. This was made by calculating cumulative incidence curves in the birth weight categories and comparing them with the Kaplan-Meier estimates.

All statistical analyses were performed using Stata version 11.2 (Stata Corp., Collage Station, TX, USA). 


\section{$\underline{\text { Results }}$}

Characteristics of the two cohorts are displayed in Tables 1 and 2. The birth weights were somewhat lower in the UBCoS cohort (women: $3.4 \mathrm{~kg}$ and men: $3.5 \mathrm{~kg}$ ) than in the ULSAM cohort $(3.6 \mathrm{~kg})$.

Table 1. Characteristics of participants in the Uppsala Birth Cohort Study (UBCoS), born 1915-29.

\begin{tabular}{lrr}
\hline & UBCOS Women & UBCoS Men \\
\hline $\mathrm{N}$ & 5257 & 5636 \\
Birth weight, kg & $3.4(0.5)$ & $3.5(0.5)$ \\
Parity, median (range) & $2(1,16)^{\mathrm{a}}$ & $2(1,16)^{\mathrm{a}}$ \\
Gestational age, completed weeks & $39.6(2.0)$ & $39.5(2.0)$ \\
Birth length, cm & $50.5(2.2)$ & $51.3(2.2)$ \\
Mother's age, years & $28.4(6.5)$ & $28.4(6.4)$ \\
Social class at birth, $n(\%)$ & & \\
$\quad$ Non-manual worker & $780(14.8)$ & $854(15.2)$ \\
Self-employed/farmer & $878(16.7)$ & $1009(17.9)$ \\
Manual worker & $3179(60.5)$ & $3315(58.8)$ \\
Other & $420(8.0)$ & $458(8.1)$ \\
One or more Charlson's comorbidity before age 50, n & & \\
$(\%)$ & $149(2.8)$ & $137(2.4)$ \\
\hline
\end{tabular}

Values are mean (SD) unless otherwise stated. ${ }^{\text {a }}$ Values are median (range). 
Table 2. Characteristics of 1,334 participants in the Uppsala Longitudinal Study of Adult Men (ULSAM), born 1920-24.

\begin{tabular}{|c|c|}
\hline & ULSAM Men \\
\hline \multicolumn{2}{|l|}{ Variables at birth } \\
\hline Birth weight, kg & $3.6(0.5)$ \\
\hline Born at Uppsala University Hospital, n (\%) & $616(46.2)$ \\
\hline \multicolumn{2}{|l|}{ Variables at age 50 years } \\
\hline Weight, kg & $77.9(11.2)$ \\
\hline Height, m & $1.76(0.06)$ \\
\hline BMI, $\mathrm{kg} / \mathrm{m}^{2}$ & $25.1(3.2)$ \\
\hline \multicolumn{2}{|l|}{ Smoking status, $n(\%)$} \\
\hline Current smoker & $696(52.2)$ \\
\hline Former smoker & $298(22.3)$ \\
\hline Never smoker & $340(25.5)$ \\
\hline Married, n (\%) & $1082(81.1)$ \\
\hline \multicolumn{2}{|l|}{ Social class, $n(\%)$} \\
\hline High & $156(11.7)$ \\
\hline Middle & $529(39.7)$ \\
\hline Low & $649(48.7)$ \\
\hline One or more Charlson’s comorbidity, n (\%) & $25(1.9)$ \\
\hline \multicolumn{2}{|l|}{ DXA measurements at age 82 years } \\
\hline Bone mineral density, total body, ${ }^{a} \mathrm{~g} / \mathrm{cm}^{2}$ & $1.19(0.10)$ \\
\hline T-score, total body ${ }^{\mathrm{a}}$ & $-0.36(1.21)$ \\
\hline Bone mineral density, lumbar spine, ${ }^{\mathrm{b}} \mathrm{g} / \mathrm{cm}^{2}$ & $1.33(0.26)$ \\
\hline T-score, lumbar spine ${ }^{b}$ & $0.72(2.14)$ \\
\hline Bone mineral density, total hip, ${ }^{\mathrm{c}} \mathrm{g} / \mathrm{cm}^{2}$ & $0.99(0.15)$ \\
\hline T-score, total hip ${ }^{c}$ & $-0.74(1.06)$ \\
\hline Bone mineral content total body, ${ }^{\mathrm{a}} \mathrm{g}$ & $3018(408)$ \\
\hline Bone mineral content, lumbar spine, ${ }^{\mathrm{b}} \mathrm{g}$ & $70(18)$ \\
\hline Bone mineral content, total hip ${ }^{\mathrm{c}} \mathrm{g}$ & $39(7)$ \\
\hline
\end{tabular}

During 282,069 person-years at risk in UBCoS we observed 2,796 fractures of which 717 were hip fractures. $62 \%$ of all fractures and $64 \%$ of hip fractures occurred in women. The mean age of fracture was 72 years and of hip fracture 73 years. We observed 35,725 person-years in ULSAM. During this time, we observed 335 fractures, of which 102 were hip fractures. The subjects were followed between 50 and 94 years in UBCoS and between 50 and 90 years in ULSAM. The Kaplan-Meier failure curves for any fracture and hip fracture in the cohorts are displayed in Supplemental Figure 2. Cumulative incidence curves indicated that competing events only have minor influence on our results (Supplemental Figure 3).

In UBCoS, birth weight was not associated with any fracture (adjusted HR per kg birth weight, 1.01; 95\% CI, 0.94-1.09) or with hip fracture (adjusted HR, 1.06; 95\% CI, 0.911.23 ) in analyses adjusted for sex and social class at birth. Further adjustment for mother's parity, gestational age, and comorbidity did not markedly change the estimates with HR 1.03 (95\% CI, 0.95-1.12) for any fracture and 1.04 (0.88-1.23) for hip fracture. 
In analyses stratified by sex there was no evidence of an association with any fracture in either sex ( $\mathrm{p}=0.518$ for sex interaction; see also Tables 3 and 4). There was, however, marginal evidence of a sex interaction with respect to hip fracture $(\mathrm{p}=0.045)$; although there was no evidence that birth weight predicted hip fracture rate among UBCoS women, there was a trend towards increasing rate of hip fracture with increasing birth weight among UBCoS men (adjusted HR per kg birth weight, 1.27; 95\% CI, 0.99-0.62; Table 4). In ULSAM there was no association in men between birth weight and rate of any fracture or hip fracture (Table 5). In all these analyses there was generally little or no evidence of non-linearity for the effects of birth weight (all $p>0.01$, most $p>0.1$ ). Using the highest $(\geq 4.0 \mathrm{~kg}$ ) instead of the middle (3.0-3.4 kg) birth weight category as comparison group did not reveal any statistically significant differences. Among low birth weight infants $(<2.5 \mathrm{~kg})$, however, the number of hip fracture cases was low $(\mathrm{N}=22$ for UBCoS women, $\mathrm{N}=4$ for UBCoS men, $\mathrm{N}=2$ for ULSAM men), leaving these analyses underpowered. As a sensitivity analysis, we used any non-hip fracture as an outcome. Among UBCoS women we observed 1290 such fractures and the adjusted HR per $1 \mathrm{~kg}$ increase in birth weight was 0.99 (95\% CI, 0.88-1.10). There were 757 non-hip fractures among UBCoS men; adjusted HR: 1.02 (95\% CI, 0.88-1.18), and 266 among ULSAM men; adjusted HR, 0.95 (95\% CI, 0.75-1.21). Adjusted HRs comparing the lowest $(<2.5$ $\mathrm{kg}$ ) with the middle (3.0-3.4 kg) birth weight group were 1.11 (95\% CI, 0.84-1.47) for UBCoS women, 1.40 (95\% CI, 0.89-2.18) for UBCoS men, and 1.33 (95\% CI, 0.54-3.28) for ULSAM men. 
Table 3. Birth weight and rate of fracture after age 50 years among 5,257 Swedish singleton women in the Uppsala Birth Cohort, born $1915-29$

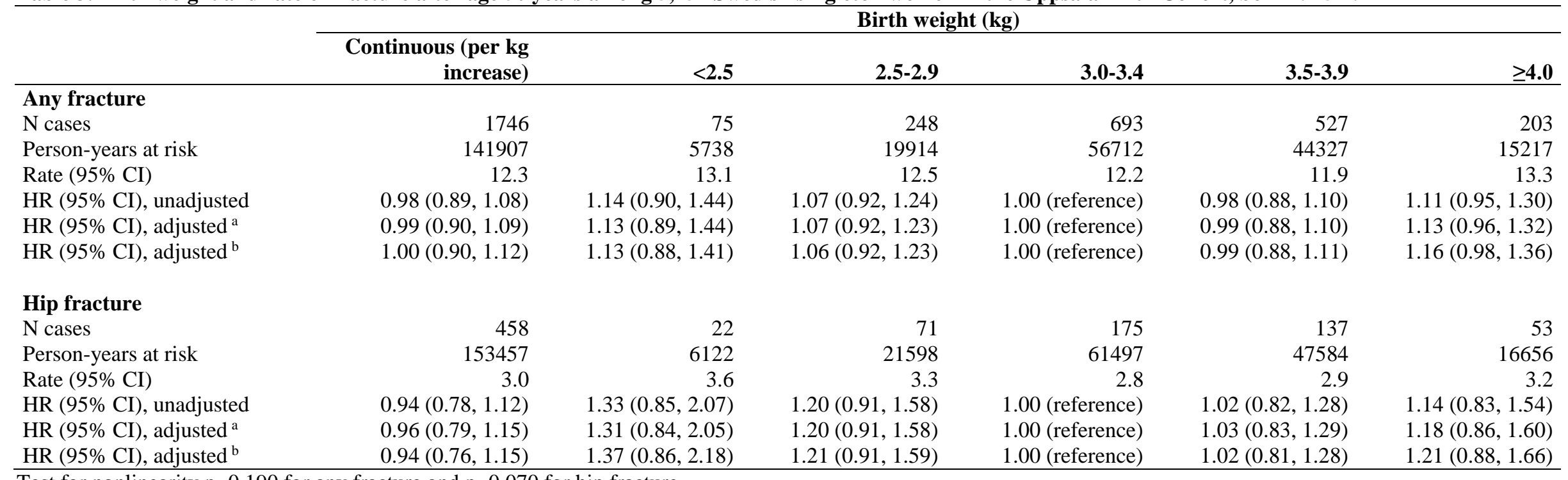

Test for nonlinearity $\mathrm{p}=0.190$ for any fracture and $\mathrm{p}=0.070$ for hip fracture.

${ }^{a}$ Adjusted for social class at birth.

b Adjusted for social class at birth, mother's parity, gestational age, comorbidity. The analysis for hip fracture was additionally adjusted for previous (non-hip) fracture. 
Table 4. Birth weight and rate of fracture after age 50 years among 5,636 Swedish singleton men in the Uppsala Birth Cohort, born 1915-29

\begin{tabular}{|c|c|c|c|c|c|c|}
\hline & \multicolumn{6}{|c|}{ Birth weight (kg) } \\
\hline & $\begin{array}{r}\text { Continuous (per kg } \\
\text { increase) }\end{array}$ & $<2.5$ & $2.5-2.9$ & 3.0-3.4 & $3.5-3.9$ & $\geq 4.0$ \\
\hline Any fracture & & & & & & \\
\hline $\mathrm{N}$ cases & 1050 & 29 & 99 & 332 & 414 & 176 \\
\hline Person-years at risk & 140450 & 3116 & 14155 & 48189 & 51213 & 23776 \\
\hline Rate $(95 \%$ CI) & 7.5 & 9.3 & 7.0 & 6.9 & 8.1 & 7.4 \\
\hline HR (95\% CI), unadjusted & $1.03(0.91,1.16)$ & $1.39(0.95,2.03)$ & $1.02(0.82,1.28)$ & 1.00 (reference) & $1.17(1.01,1.35)$ & $1.06(0.88,1.27)$ \\
\hline HR $(95 \%$ CI $)$, adjusted ${ }^{a}$ & $1.04(0.92,1.18)$ & $1.39(0.95,2.04)$ & $1.01(0.81,1.27)$ & 1.00 (reference) & $1.17(1.02,1.36)$ & $1.07(0.89,1.29)$ \\
\hline HR $\left(95 \%\right.$ CI), adjusted ${ }^{b}$ & $1.07(0.94,1.23)$ & $1.33(0.89,1.97)$ & $1.00(0.79,1.25)$ & 1.00 (reference) & $1.19(1.02,1.37)$ & $1.09(0.90,1.32)$ \\
\hline Hip fracture & & & & & & \\
\hline $\mathrm{N}$ cases & 259 & 4 & 18 & 84 & 107 & 46 \\
\hline Person-years at risk & 147687 & 3372 & 14786 & 50544 & 53975 & 25011 \\
\hline Rate $(95 \%$ CI) & 1.8 & 1.2 & 1.2 & 1.7 & 2.0 & 1.8 \\
\hline HR (95\% CI), unadjusted & $1.26(0.99,1.61)$ & $0.72(0.27,1.98)$ & $0.74(0.44,1.23)$ & 1.00 (reference) & $1.19(0.89,1.58)$ & $1.09(0.76,1.56)$ \\
\hline HR (95\% CI), adjusted ${ }^{a}$ & $1.27(0.99,1.62)$ & $0.73(0.27,2.00)$ & $0.74(0.44,1.23)$ & 1.00 (reference) & $1.19(0.89,1.59)$ & $1.10(0.77,1.58)$ \\
\hline HR $\left(95 \%\right.$ CI), adjusted ${ }^{\mathrm{b}}$ & $1.25(0.96,1.64)$ & $0.69(0.25,1.94)$ & $0.74(0.44,1.24)$ & 1.00 (reference) & $1.15(0.86,1.53)$ & $1.10(0.76,1.60)$ \\
\hline
\end{tabular}

Test for nonlinearity $\mathrm{p}=0.778$ for any fracture and $\mathrm{p}=0.011$ for hip fracture.

${ }^{a}$ Adjusted for social class at birth.

${ }^{b}$ Adjusted for social class at birth, mother's parity, gestational age, comorbidity. The analysis for hip fracture was additionally adjusted for previous (non-hip) fracture. 
Table 5. Birth weight and rate of fracture after age 50 years among 1,334 Swedish men in the Uppsala Longitudinal Study of Adult Men, born 1920-24

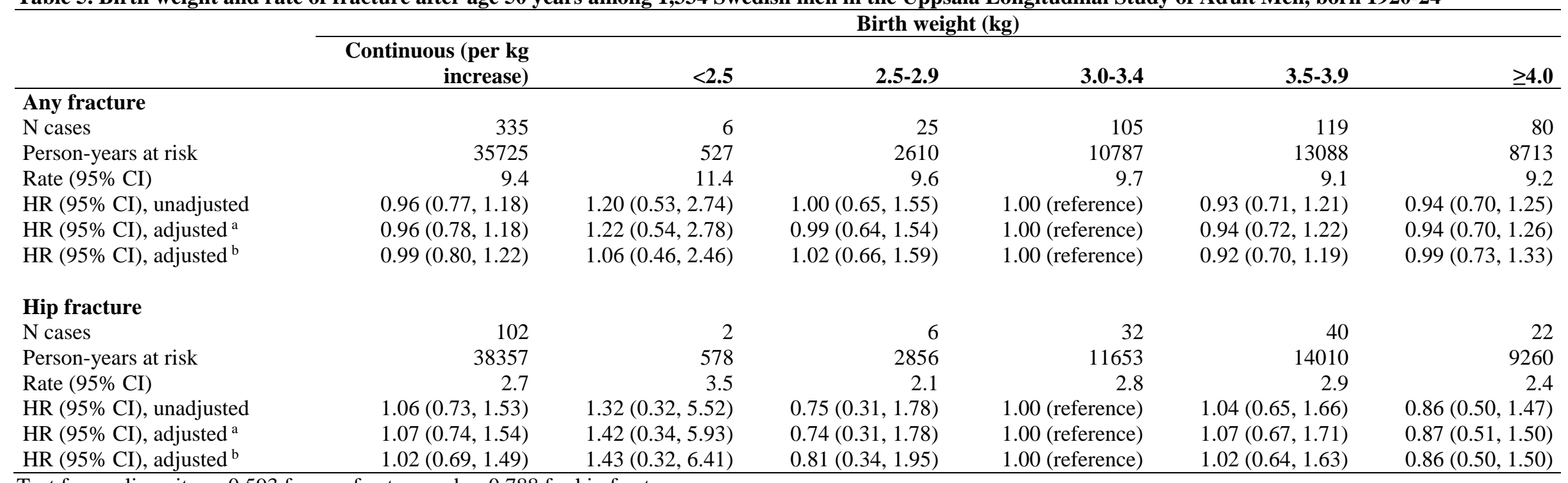

Test for nonlinearity $\mathrm{p}=0.593$ for any fracture and $\mathrm{p}=0.788$ for hip fracture.

${ }^{\text {a }}$ Adjusted for social class at age 50 .

${ }^{\mathrm{b}}$ Adjusted for social class, height, body mass index, smoking status and comorbidity. The analysis for hip fracture was additionally adjusted for previous (nonhip) fracture. 
We combined our results in a meta-analysis to get an overall estimate of the association between birth weight and fracture in our cohorts. The pooled adjusted hazard ratio for any fracture per $1 \mathrm{~kg}$ increase in birth weight was 1.00 (95\% CI, 0.93-1.08) and for hip fracture 1.03 (95\% CI, 0.84-1.27; Figure 2). Comparing those with the lowest birth weight $(<2.5 \mathrm{~kg})$ with the middle birth weight category $(3.0-3.4 \mathrm{~kg})$, the pooled adjusted hazard ratio for any fracture was 1.21 (95\% CI, 0.99-1.47) and that for hip fracture was 1.26 (95\% CI, 0.85-1.86), again with few hip fracture cases in the lowest group of birth weight.

Figure 2. Adjusted hazard ratios and $95 \%$ confidence intervals (CI) per kg increase in birth weight for fracture of any type and of the hip for participants in Uppsala Birth Cohort Study (UBCoS) and in Uppsala Longitudinal Study of Adult Men (ULSAM).

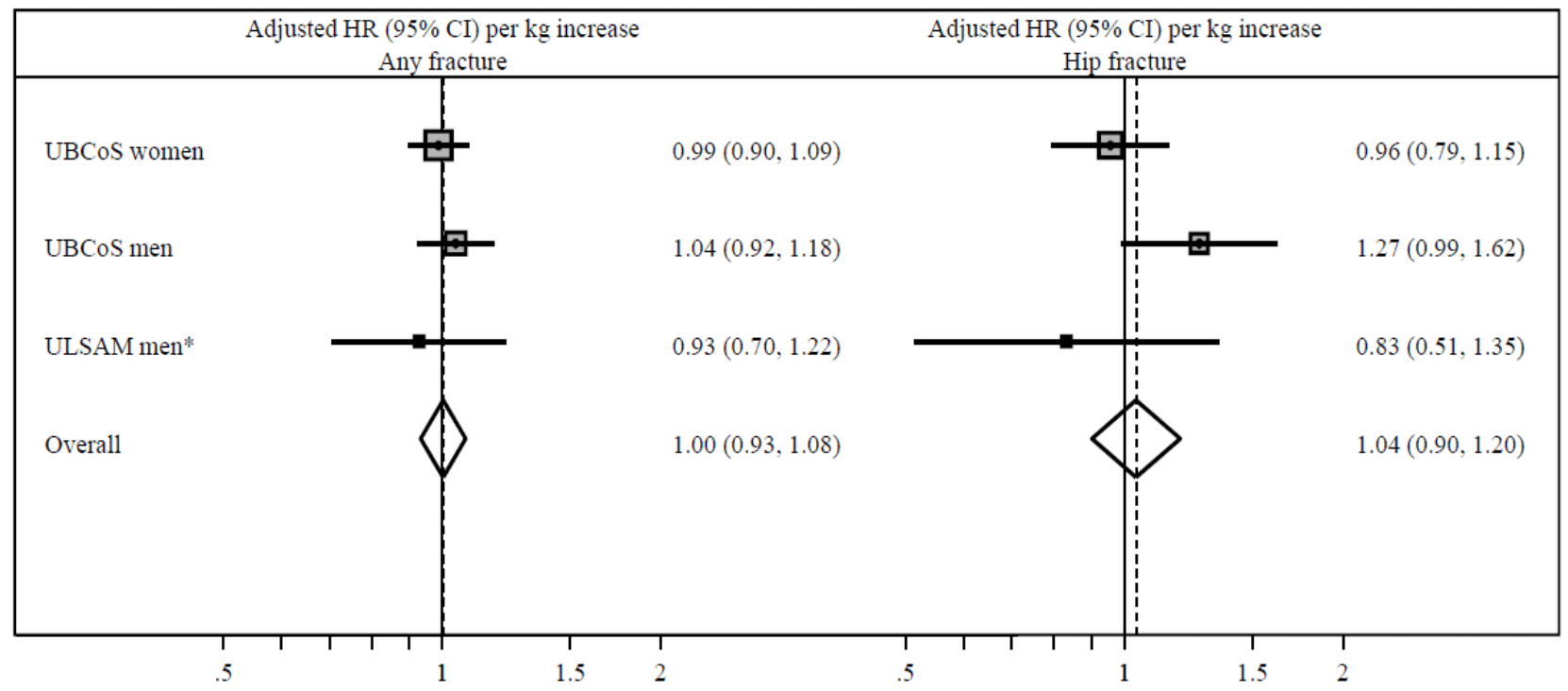

Estimates adjusted for social class at birth (UBCoS) or at age 50 (ULSAM). ULSAM men who were born at Uppsala University Hospital $(\mathrm{n}=616)$ were excluded from this estimate since they are already represented in the group of UBCoS men

Stratifying by age at fracture (above or below age 70 years; Supplemental Tables 1 and 2) did not change our results.

Birth length, gestational age, and birth weight standardized to gestational age were not associated with fracture risk in UBCoS (Supplemental Table 3).

We adjusted our estimates for adult height in a subset of UBCoS men with adult height data $(\mathrm{N}=1,241)$ and in the ULSAM men not included in this UBCoS subset $(\mathrm{N}=1,261)$. The pooled HRs per $1 \mathrm{~kg}$ increase in birth weight, adjusted for social class at birth or in adulthood, for any fracture $(\mathrm{N}=449)$ and hip fracture $(\mathrm{N}=129)$ were 1.04 (95\% CI, 0.87$1.25)$ and 0.99 (95\% CI, 0.71-1.38). HRs after further adjustment for adult height were 1.00 (95\% CI, 0.83-1.20) for any fracture and 0.91 (95\% CI, 0.65-1.28) for hip fracture. Height was associated with increased risk of hip fracture in both UBCoS men and in 
ULSAM; HR per $1 \mathrm{~cm}$ increase: 1.04 (95\% CI, 1.00-1.08) and 1.03 (1.00-1.06). Formal tests for interaction between birth weight and adult height were not statistically significant in either cohort or for any outcome (all $\mathrm{p}>0.2$ for interaction).

Finally, we assessed whether birth weight was associated with bone mineral density and content at age 82 in ULSAM, adjusted for age at DXA and social class. Adjusted means in groups of birth weight are shown in Figure 3. Birth weight was not associated with total body BMD (unadjusted $\beta, 0.004 \mathrm{~g} / \mathrm{cm}^{2} ; 95 \% \mathrm{CI},-0.02$ to 0.03 ; adjusted $\beta, 0.001$ $\mathrm{g} / \mathrm{cm}^{2} ; 95 \% \mathrm{CI}:-0.02$ to 0.02 ) or with BMD at the lumbar spine (unadjusted $\beta, 0.01$ $\mathrm{g} / \mathrm{cm}^{2} ; 95 \% \mathrm{CI},-0.05$ to 0.06$)$; adjusted $\beta,-0.001 \mathrm{~g} / \mathrm{cm}^{2} ; 95 \% \mathrm{CI},-0.06$ to 0.06$)$ or total hip (unadjusted $\beta,-0.001 \mathrm{~g} / \mathrm{cm}^{2} ; 95 \% \mathrm{CI},-0.04$ to 0.04 ; adjusted $\beta,-0.01 \mathrm{~g} / \mathrm{cm}^{2} ; 95 \% \mathrm{CI}$, -0.04 to 0.03 ). There was a positive association between birth weight and total body BMC (unadjusted $\beta, 136 \mathrm{~g}$; 95\% CI, 44-228 g; adjusted $\beta, 133 \mathrm{~g}$; 95\% CI, 39-227). The association was attenuated when further and mutual adjustment was made for BMI and height at time of DXA (age 82 years): adjusted $\beta$ for total body BMC, $41 \mathrm{~g}(95 \% \mathrm{CI},-43$ to 126). Birth weight was not associated with $\mathrm{BMC}$ at the total hip (unadjusted $\beta, 1.37 \mathrm{~g}$; $95 \% \mathrm{CI},-0.18$ to 2.93 ; adjusted $\beta, 1.22 \mathrm{~g}(95 \% \mathrm{CI},-0.35$ to 2.78$)$ or the lumbar spine (unadjusted $\beta, 1.09 \mathrm{~g} ; 95 \% \mathrm{CI},-2.98$ to 5.16 ; adjusted $\beta, 1.08 \mathrm{~g} ; 95 \% \mathrm{CI},-3.1$ to 5.2 ). Birth length ( $\mathrm{n}=244-266$, depending on DXA site) was not associated with BMD, unadjusted and adjusted estimates ranging from -0.04 to $0.0004 \mathrm{~g} / \mathrm{cm}^{2}$, depending on site, or with $\mathrm{BMC}$, unadjusted and adjusted estimates ranging between $0.09 \mathrm{~g}$ (for lumbar spine BMC) and $18.0 \mathrm{~g}$ (for total body BMC). 
Figure 3. Adjusted means and $95 \%$ confidence intervals for bone mineral density (BMD) and bone mineral content (BMC) measured by dual $x$-ray absortiopometry (DXA) at age 82 by birth weight for participants in the Uppsala Longitudinal Study of Adult Men (ULSAM).
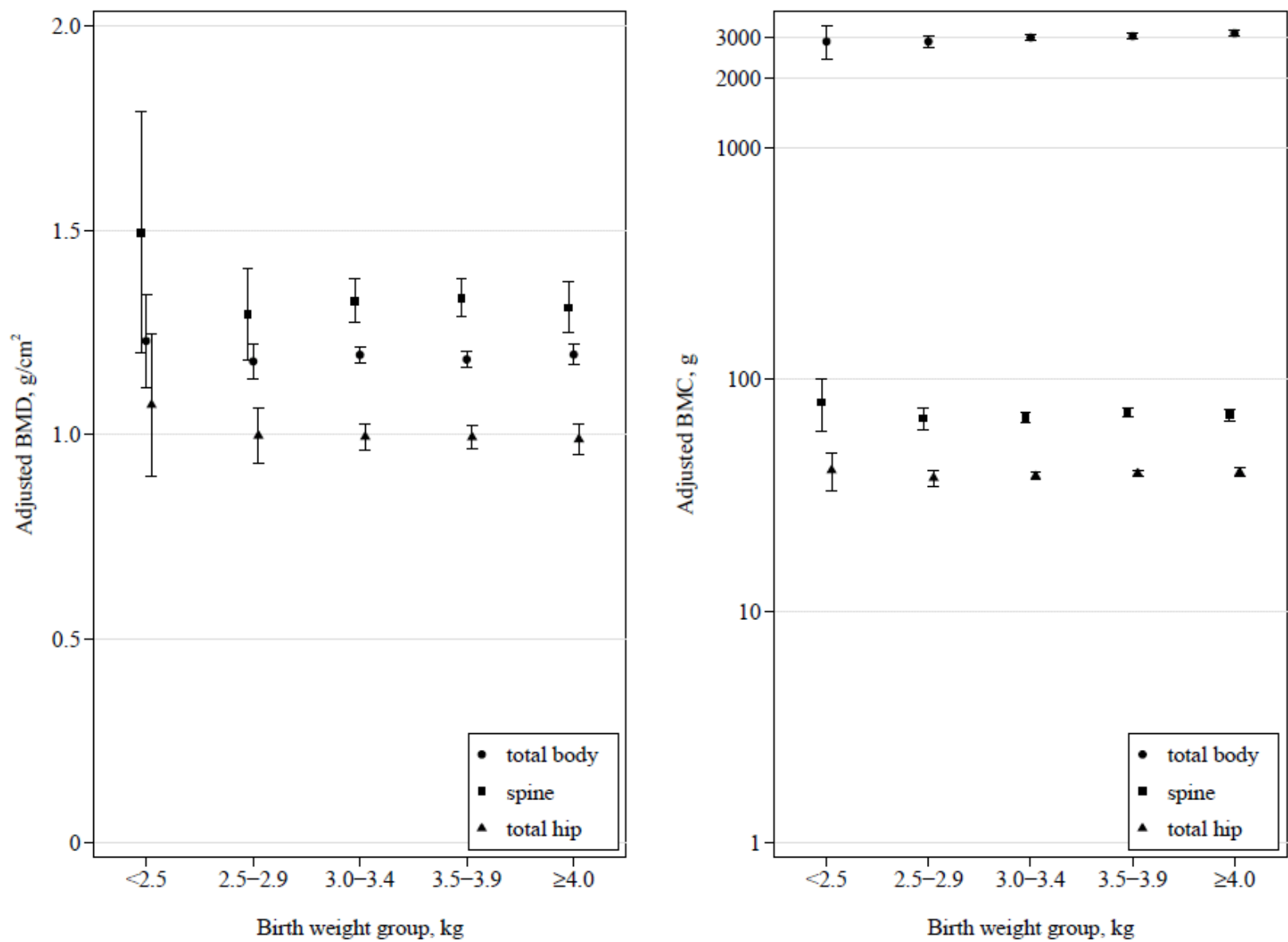

$\mathrm{N}=300$ for total body measurements, $\mathrm{N}=303$ for spine, and $\mathrm{N}=280$ for total hip. There were 3 men in the lowest birth weight group for all measurements. Covariates included were age at DXA scan and social class at age 50 .

\section{$\underline{\text { Discussion }}$}

In this study, we found no association between birth weight and risk of any type of fracture or of hip fracture. The two cohorts with register data on both birth weight and incident fractures after age 50 years until old age constitute the thus far largest study on birth weight and fracture risk.

Few studies have examined the association of birth weight with fracture outcomes, especially in old age. Increasing birth length and birth weight were associated with increased risk of fracture until age 11 in a Brazilian study, ${ }^{(12)}$ whereas birth length, but not weight, was associated with fractures occurring before puberty in a study from New Zealand. ${ }^{(13)}$ In two studies of Finnish cohorts factors at birth, including weight and length, ${ }^{(10,11)} \mathrm{BMI},{ }^{(11)}$ ponderal index, head circumference, and length of gestation, ${ }^{(10)}$ 
were not associated with hip fracture risk. However, the cohorts were only followed until a maximum age of 71 years and only a modest number of fractures $\left(112^{(10)}\right.$ and $49^{(11)}$ hip fractures) were observed. The heritable contribution of hip fracture risk is larger before the age of 70 years, whereas individual lifestyle increases in importance at older ages. ${ }^{(21)}$ One might speculate that this could be true also for birth characteristics and we therefore performed analyses stratified by age. Our results were not dependent on whether the fracture occurred before or after age 70 .

Earlier studies have shown associations between size at birth and bone mineral content in adulthood, whereas associations with bone mineral density are rare. ${ }^{(2-4,6,39)} \mathrm{A}$ recent study in 60 to 64-year-old men and women demonstrated that birth weight, but even more so pre- and post-pubertal growth rate, was associated with bone strength and radius cross sectional area. ${ }^{(6)}$ In the present study, the association between birth weight and bone mineral content was largely explained by body size in adulthood, suggesting that this may be a reflection of the relation between birth weight and adult skeletal and body size. The conclusion that birth weight and adult bone metabolism are unrelated was also drawn in a recent study of birth weight discordant twins where the largest twin tended to have larger BMD but any differences in BMD were due to dissimilarities in body size. ${ }^{(5)}$

Admittedly, birth weight is one outcome of intrauterine growth and has obvious limitations as a sole indicator of potential fetal programming of fracture risk. The two previously mentioned Finnish studies did observe that poor childhood growth ${ }^{(10)}$ and thinness in childhood ${ }^{(11)}$ were risk factors for hip fracture. The findings could be a result of intrauterine programming but also heritable factors ${ }^{(15)}$ and childhood lifestyle are potential explanations. Thinness and low weight gain also in adulthood are associated with future fracture risk. ${ }^{(14)}$ In several studies, catch-up growth in persons born small at birth, who grow to average size or larger postnatally, has been related to increased risk of cardiovascular disease. ${ }^{(24,40,41)}$ Being tall is in many studies associated with an increased hip fracture risk, ${ }^{(42,43)}$ an association observed also in the present study. However, height may be differentially associated with different types of fracture. ${ }^{(44)}$ We adjusted our estimates for adult height with minor influences on our estimates. We did not have information on a large enough sample to study whether men who were small at birth but grew to be above median height had an increased risk of fracture.

Because our cohorts originate in the early $20^{\text {th }}$ century, the premature children of very low birth weight that can be rescued with today's neonatal care are lacking from our data. However, based on our results, it is possible to make inferences regarding the normal range of birth weight. Previous studies have shown inconsistent results regarding prematurity or gestational age and bone health. ${ }^{(39,45,46)}$ Within the range of 28-47 completed weeks of pregnancy, based on the last menstruation date, we could see no association between gestational age per se or birth weight standardized to gestational age and future fracture risk. In an attempt to limit the influence of potential misclassification of gestational age, we excluded those with a gestational age $>42$ weeks, which did not alter our results (not shown). 


\section{Strengths and limitations}

The major strength of the present study is the use of two well-defined and largely independent cohorts. Our cohorts are based in Sweden, a country among those with the highest incidence of fractures in the world. ${ }^{(47)}$ In order to capture the influence of birth weight on actual hip fracture risk, a long follow-up time is necessary. This, in combination with the high quality registers and possibility of tracing individuals ${ }^{(48)}$ over a long follow-up time with limited loss to follow-up, meant that our study was wellpowered for examining associations between birth weight and fracture risk. Our primary exposure of birth weight was measured with unusual accuracy of cohorts of this age, and has previously been demonstrated to show the expected associations with risk of cardiovascular disease and type 2 diabetes in these cohorts with similar or lower number of outcomes..$^{(22,24,49-52)} \mathrm{We}$ were also able to study the association of birth weight with measurements of BMD and BMC in a subgroup of elderly men and observe an association with total body BMC, as previously shown. ${ }^{(2-4,6,39,53)}$

Nevertheless, one important limitation in the ULSAM study is that not all birth records were traced $(57 \%)$ and that around half of the information that was traced was retrieved from midwives' registers relating to a home birth. Although midwives' birth records are less informative and probably with less accurate measurements of the birth weight (contributing to potential misclassification) than those kept at hospitals, having both types of deliveries in our cohort improves the generalizability of the results. In the early $20^{\text {th }}$ century giving birth at home was more common among comparatively affluent urban women with uncomplicated pregnancies. ${ }^{25,54)}$ This difference is also reflected in the somewhat higher mean birth weight in ULSAM than in UBCoS. On the other hand, although UBCoS is hospital based, its participants are representative of the region and Sweden in terms of characteristics such as infant mortality ${ }^{(55)}$ and subsequent fertility. ${ }^{(32)}$ Moreover, the similarity of our findings between the two cohorts, each with their complementary strengths, gives some confidence to the robustness of our findings.

\section{Conclusion}

Based on results from two Swedish cohorts with register data on both size at birth and incident fractures from age 50 until old age, we conclude that birth weight does not seem to be a major independent contributor to frailty fractures in our population.

\section{Disclosures}

Results and views of the present study represent the authors and not necessarily any official views of the Medical Products Agency where one author is employed (BZ). We have no other disclosures to report. 


\section{$\underline{\text { References }}$}

1. Cooper C, Westlake S, Harvey N, Javaid K, Dennison E, Hanson M. Review: developmental origins of osteoporotic fracture. Osteoporos Int. 2006;17(3):337-47.

2. Schlüssel MM, Dos Santos Vaz J, Kac G. Birth weight and adult bone mass: a systematic literature review. Osteoporos Int. 2010;21(12):1981-91.

3. Baird J, Kurshid MA, Kim M, Harvey N, Dennison E, Cooper C. Does birthweight predict bone mass in adulthood? A systematic review and meta-analysis. Osteoporos Int. 2011;22(5):1323-34.

4. Callréus M, McGuigan F, Åkesson K. Birth weight is more important for peak bone mineral content than for bone density: the PEAK-25 study of 1,061 young adult women. Osteoporos Int. 2013;24(4):1347-55.

5. Frost M, Petersen I, Andersen T, et al. Birth weight and adult bone metabolism are unrelated. Results from birth weight discordant monozygotic twins. J Bone Miner Res. 2013;18(12):2561-9.

6. Kuh D, Wills AK, Shah I, et al. Growth From Birth to Adulthood and Bone Phenotype in Early Old Age: A British Birth Cohort Study. J Bone Miner Res. 2014;29(1):12333.

7. Steer CD, Tobias JH. Insights into the programming of bone development from the Avon Longitudinal Study of Parents and Children (ALSPAC). Am J Clin Nutr. 2011;94(6 Suppl):1861S-4S.

8. Jensen RB, Vielwerth S, Frystyk J, et al. Fetal growth velocity, size in early life and adolescence, and prediction of bone mass: association to the GH-IGF axis. J Bone Miner Res. 2008;23(3):439-46.

9. Javaid MK, Cooper C. Prenatal and childhood influences on osteoporosis. Best Pract Res Clin Endocrinol. 2002;16(2):349-67.

10. Cooper C, Eriksson JG, Forsén T, Osmond C, Tuomilehto J, Barker DJP. Maternal Height, Childhood Growth and Risk of Hip Fracture in Later Life: A Longitudinal Study. Osteoporos Int. 2001;12(8):623-9.

11. Javaid M, Eriksson J, Kajantie E, et al. Growth in childhood predicts hip fracture risk in later life. Osteoporos Int. 2011;22(1):69-73.

12. Hallal P, Siqueira F, Menezes A, Araújo C, Norris S, Victora C. The role of early life variables on the risk of fractures from birth to early adolescence: a prospective birth cohort study. Osteoporos Int. 2009;20:1873-9.

13. Jones IE, Williams SM, Goulding A. Associations of birth weight and length, childhood size, and smoking with bone fractures during growth: evidence from a birth cohort study. Am J Epidemiol. 2004;159(4):343-50.

14. Farahmand BY, Michaëlsson K, Baron JA, Persson PG, Ljunghall S. Body size and hip fracture risk. Swedish Hip Fracture Study Group. Epidemiology. 2000;11(2):2149.

15. Wagner H, Melhus H, Pedersen NL, Michaelsson K. Genetic influence on bone phenotypes and body composition: a Swedish twin study. J Bone Miner Metab. 2013;31(6):681-9.

16. Koupilová I, Leon DA, Vågerö D. Can confounding by sociodemographic and behavioural factors explain the association between size at birth and blood pressure at age 50 in Sweden? J Epidemiol Community Health. 1997;51(1):14-8. 
17. Farahmand BY, Persson PG, Michaëlsson K, et al. Socioeconomic Status, Marital Status and Hip Fracture Risk: A Population-Based Case-Control Study. Osteoporos Int. 2000;11(9):803-8.

18. Brennan SL, Pasco JA, Urquhart DM, Oldenburg B, Hanna F, Wluka AE. The association between socioeconomic status and osteoporotic fracture in populationbased adults: a systematic review. Osteoporos Int. 2009;20(9):1487-97.

19. Crandall CJ, Han W, Greendale GA, et al. Socioeconomic status in relation to incident fracture risk in the Study of Women's Health Across the Nation. Osteoporos Int. 2014.

20. Brennan SL, Pasco JA, Urquhart DM, Oldenburg B, Wang Y, Wluka AE. Association between socioeconomic status and bone mineral density in adults: a systematic review. Osteoporos Int. 2011;22(2):517-27.

21. Wagner H, Melhus H, Pedersen NL, Michaëlsson K. Heritable and environmental factors in the causation of clinical vertebral fractures. Calcif Tissue Int. 2012;90(6):458-64.

22. Koupil I. The Uppsala studies on developmental origins of health and disease. J Intern Med. 2007;261(5):426-36.

23. Byberg L, Melhus H, Gedeborg R, et al. Total mortality after changes in leisure time physical activity in 50 year old men: 35 year follow-up of population based cohort. BMJ. 2009;338:b688.

24. Leon DA, Koupilova I, Lithell HO, et al. Failure to realise growth potential in utero and adult obesity in relation to blood pressure in 50 year old Swedish men. BMJ. 1996;312:401-6.

25. Koupilová I. Fetal growth, social factors and circulatory diseases [dissertation]. Uppsala: Uppsala University; 1997.

26. Michaëlsson K, Olofsson H, Jensevik K, et al. Leisure physical activity and the risk of fracture in men. PLoS Med. 2007;4(6):e199.

27. Naessén T, Parker R, Persson I, Zack M, Adami H-O. Time trends in incidence rates of first hip fracture in the Uppsala health care region, Sweden, 1965-1983. Am J Epidemiol. 1989;130(2):289-99.

28. Michaëlsson K, Baron JA, Farahmand BY, et al. Hormone replacement therapy and risk of hip fracture: population based case-control study. The Swedish Hip Fracture Study Group. BMJ. 1998;316(7148):1858-63.

29. Michaëlsson K, Melhus H, Ferm H, Ahlbom A, Pedersen NL. Genetic Liability to Fractures in the Elderly. Arch Intern Med. 2005;165(16):1825-30.

30. Bergström MF, Byberg L, Melhus H, Michaelsson K, Gedeborg R. Extent and consequences of misclassified injury diagnoses in a national hospital discharge registry. Inj Prev. 2011;17(2):108-13.

31. Michaëlsson K, Lind L, Frystyk J, et al. Serum Adiponectin in Elderly Men Does Not Correlate with Fracture Risk. J Clin Endocrinol Metab. 2008;93(10):4041-7.

32. Goodman A, Koupil I. Social and biological determinants of reproductive success in Swedish males and females born 1915-1929. Evol Hum Behav. 2009;30(5):329-41.

33. Modin B. Setting the scene for life. Longitudinal studies of early social disadvantage and later life chances [dissertation]. Stockholm: Centre for Health Equity Studies. Stockholm University/Karolinska Institutet; 2002.

34. Focus on Business and Labour Market, autumn 2007. Statistics Sweden, 2008. 
35. Charlson ME, Pompei P, Ales KL, MacKenzie CR. A new method of classifying prognostic comorbidity in longitudinal studies: development and validation. J Chronic Dis. 1987;40(5):373-83.

36. Quan H, Sundararajan V, Halfon P, et al. Coding algorithms for defining comorbidities in ICD-9-CM and ICD-10 administrative data. Med Care. 2005;43(11):1130-9.

37. Hernán MA, Hernández-Díaz S, Werler MM, Mitchell AA. Causal knowledge as a prerequisite for confounding evaluation: an application to birth defects epidemiology. Am J Epidemiol. 2002;155(2):176-84.

38. Harris R, Bradburn M, Deeks J, Harbord R, Altman D, Sterne J. metan: fixed- and random-effects meta-analysis. Stata J. 2008;8(1):3-28.

39. Rudäng R, Mellström D, Clark E, Ohlsson C, Lorentzon M. Advancing maternal age is associated with lower bone mineral density in young adult male offspring. Osteoporos Int. 2012;23(2):475-82.

40. Eriksson JG, Forsén T, Tuomilehto J, Winter PD, Osmond C, Barker DJP. Catch-up growth in childhood and death from coronary heart disease: longitudinal study. BMJ. 1999;318(7181):427-31.

41. Leunissen RWJ, Kerkhof GF, Stijnen T, Hokken-Koelega ACS. Effect of Birth Size and Catch-Up Growth on Adult Blood Pressure and Carotid Intima-Media Thickness. Hormone Research in Paediatrics. 2012;77(6):394-401.

42. Hemenway D, Azrael DR, Rimm EB, Feskanich D, Willett WC. Risk factors for hip fracture in US men aged 40 through 75 years. Am J Public Health. 1994;84(11):18435.

43. Hemenway D, Feskanich D, Colditz G. Body Height and Hip Fracture: A Cohort Study of 90000 Women. Int J Epidemiol. 1995;24(4):783-6.

44. Compston JE, Flahive J, Hosmer DW, et al. Relationship of Weight, Height, and Body Mass Index With Fracture Risk at Different Sites in Postmenopausal Women: The Global Longitudinal Study of Osteoporosis in Women (GLOW). J Bone Miner Res. 2014;29(2):487-93.

45. Hovi $\mathrm{P}$, Andersson $\mathrm{S}$, Järvenpää $\mathrm{AL}$, et al. Decreased bone mineral density in adults born with very low birth weight: a cohort study. PLoS Med. 2009;6(8):e1000135.

46. Backström MC, Kuusela AL, Koivisto AM, Sievänen H. Bone structure and volumetric density in young adults born prematurely: A peripheral quantitative computed tomography study. Bone. 2005;36(4):688-93.

47. Kanis J, Odén A, McCloskey E, et al. A systematic review of hip fracture incidence and probability of fracture worldwide. Osteoporos Int. 2012;23:2239-56.

48. Calltorp J, Adami H, Åström H, et al. Country profile: Sweden. Lancet. 1996;347(9001):587-97.

49. Leon DA, Lithell HO, Vågerö D, et al. Reduced fetal growth rate and increased risk of death from ischaemic heart disease: cohort study of 15000 Swedish men and women born 1915-29. BMJ. 1998;317:241-5.

50. Lithell HO, McKeigue PM, Berglund L, Mohsen R, Lithell U-B, Leon DA. Relation of size at birth to non-insulin-dependent diabetes and insulin concentrations in men aged 50-60 years. BMJ. 1996;312:406-10. 
51. McKeigue PM, Lithell HO, Leon DA. Glucose tolerance and resistance to insulinstimulated glucose uptake in men aged 70 years in relation to size at birth.

Diabetologia. 1998;41:1133-8.

52. Koupilova I, Leon DA, McKeigue PM, Lithell HO. Is the effect of low birth weight on cardiovascular mortality mediated through high blood pressure? J Hypertens. 1999;17(1):19-25.

53. Oliver H, Jameson KA, Sayer AA, Cooper C, Dennison EM. Growth in early life predicts bone strength in late adulthood: The Hertfordshire Cohort Study. Bone. 2007;41(3):400-5.

54. Sovio U, Dibden A, Koupil I. Social Determinants of Infant Mortality in a Historical Swedish Cohort. Paediatr Perinat Epidemiol. 2012;26(5):408-20.

55. Rajaleid K, Manor O, Koupil I. Does the strength of the association between foetal growth rate and ischaemic heart disease mortality differ by social circumstances in early or later life? J Epidemiol Community Health. 2008;62(5):e6. 


\section{$\underline{\text { Supplementary Material }}$}

Supplemental Figure 1a. Directed Acyclic Graph for the identification of potential confounding paths for the association between birth weight and fracture in the Uppsala Birth Cohort Study (UBCoS), using dagitty.net. Dashed arrows represent uncertain causal effects. Superscript letters denote models.

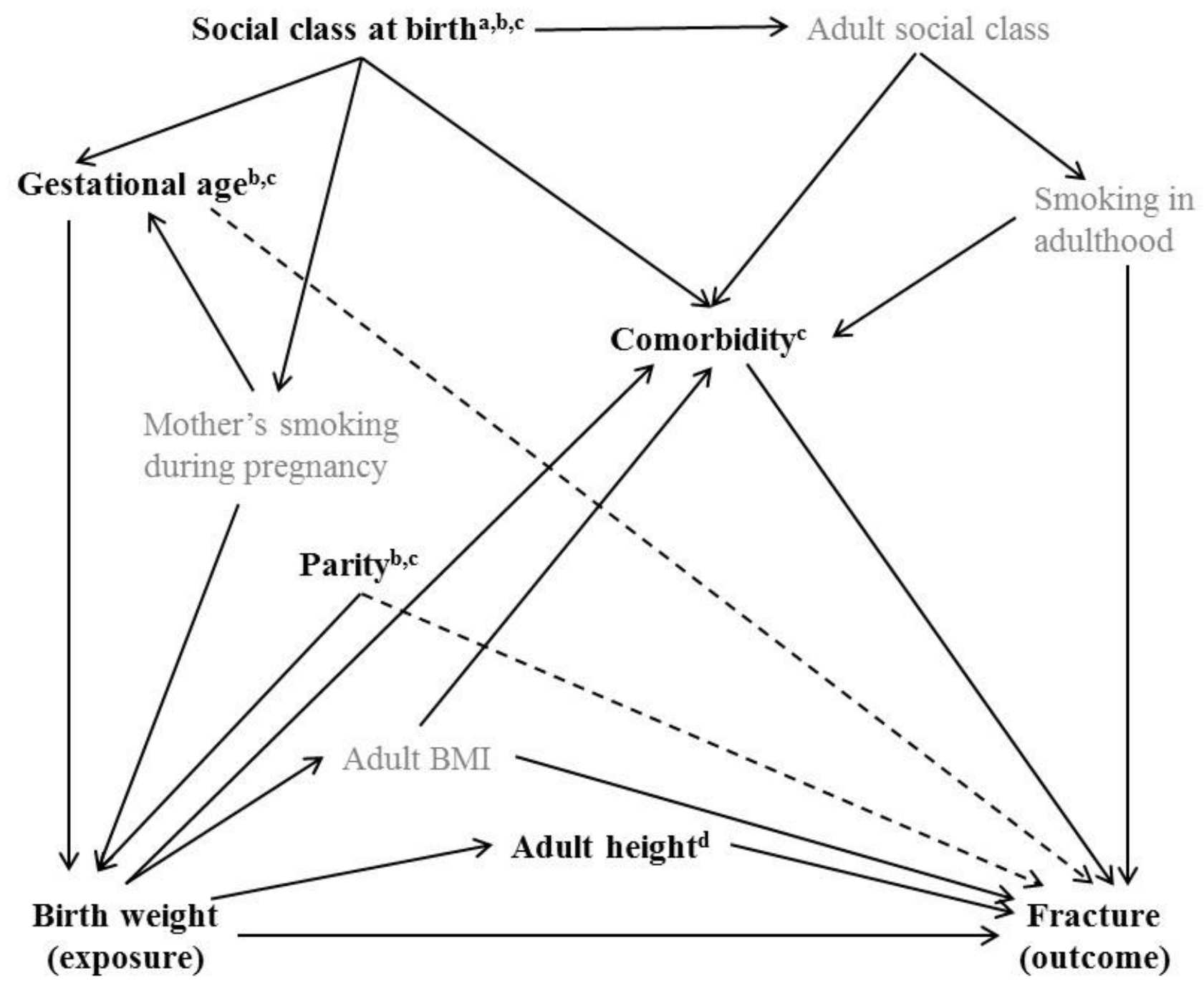

In a first evaluation, the dashed arrows were not included and social class at birth was identified as a single confounding factor, representing our main model, model a. In a second evaluation where the dashed arrows were included, social class at birth, gestational age and parity were identified as confounding factors; these were included in the second adjusted model, model b. Social class at birth, gestational age, parity, and comorbidity were included in model c. When hip fracture was the outcome, previous non-hip fracture was also included in model c. In a subset of UBCoS men with information on adult height, social class at birth and adult height were included in model $\mathrm{d}$. 
Supplemental Figure 1b. Directed Acyclic Graph for the identification of potential confounding paths for the association between birth weight and fracture in the Uppsala Longitudinal Study of Adult Men (ULSAM), using dagitty.net. Dashed arrows represent uncertain causal effects and since information on gestational age and parity was not available in ULSAM, these were not included. Superscript letters denote models.

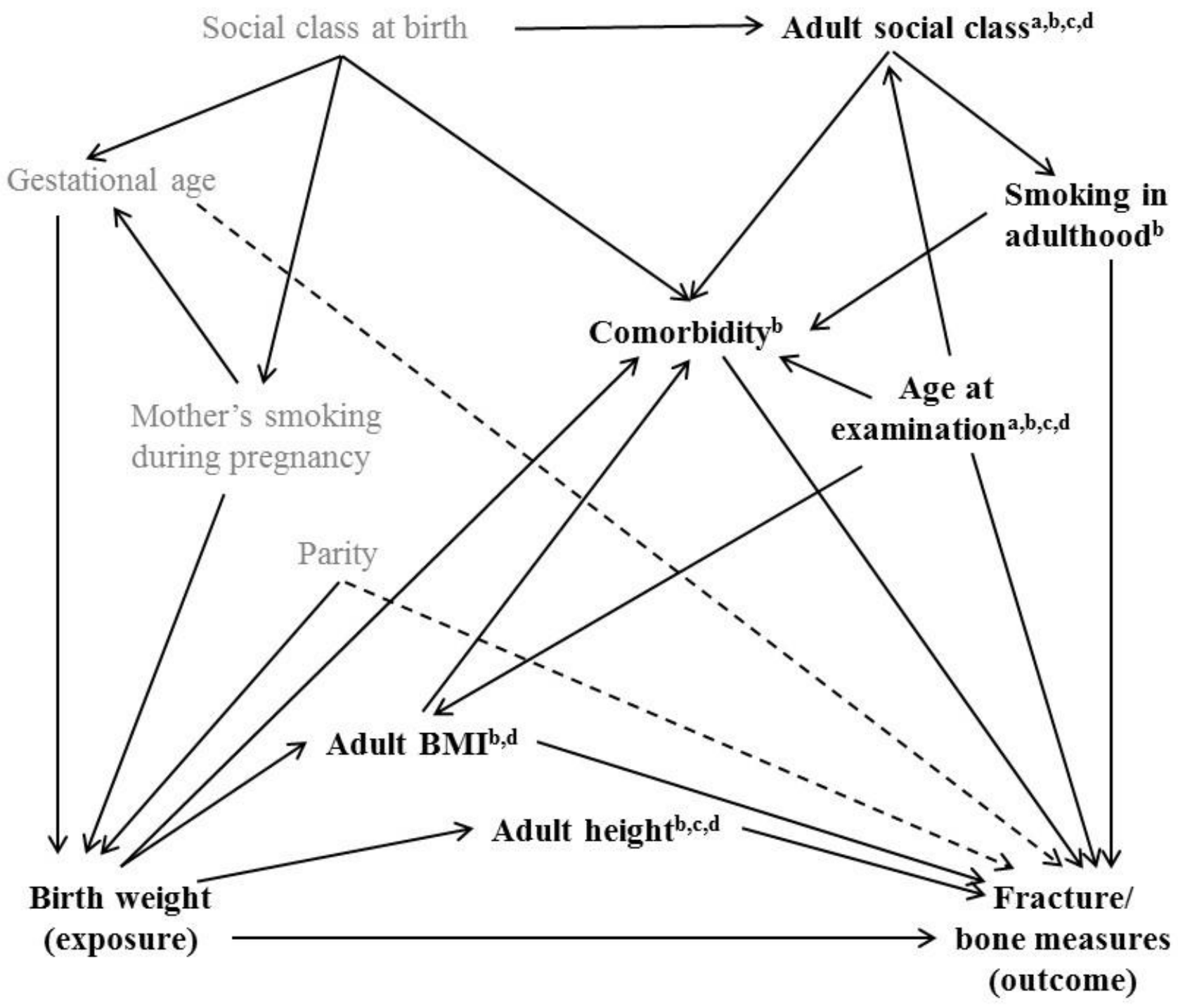

In a first evaluation, social class at birth was identified as a single confounding factor, and we used adult social class as a proxy for that, representing our main model, model a, in which age at examination also was included. Omitting age at examination did not change the results. In a second adjusted model, model b, we included adult social class, age at examination, adult height and weight, comorbidity and smoking. When hip fracture was the outcome, previous non-hip fracture was additionally included in model b. Model $\mathrm{c}$ was performed to investigate whether adult height mediated the association between birth weight and fracture and additionally included as covariates adult social class and age at examination. In analyses of bone mineral density and content as outcomes, we used model a and model d, also adjusting for adult BMI and height. 
Supplemental Figure 2. Kaplan-Meier failure curves for any fracture and hip fracture in the Uppsala Birth Cohort (UBCoS), Swedish singleton women $(n=5,257)$ and men $(n=5,636)$ born 1915-29, and the Uppsala Longitudinal Study of Adult Men (ULSAM), Swedish men (n=1,321) born 1920-24)

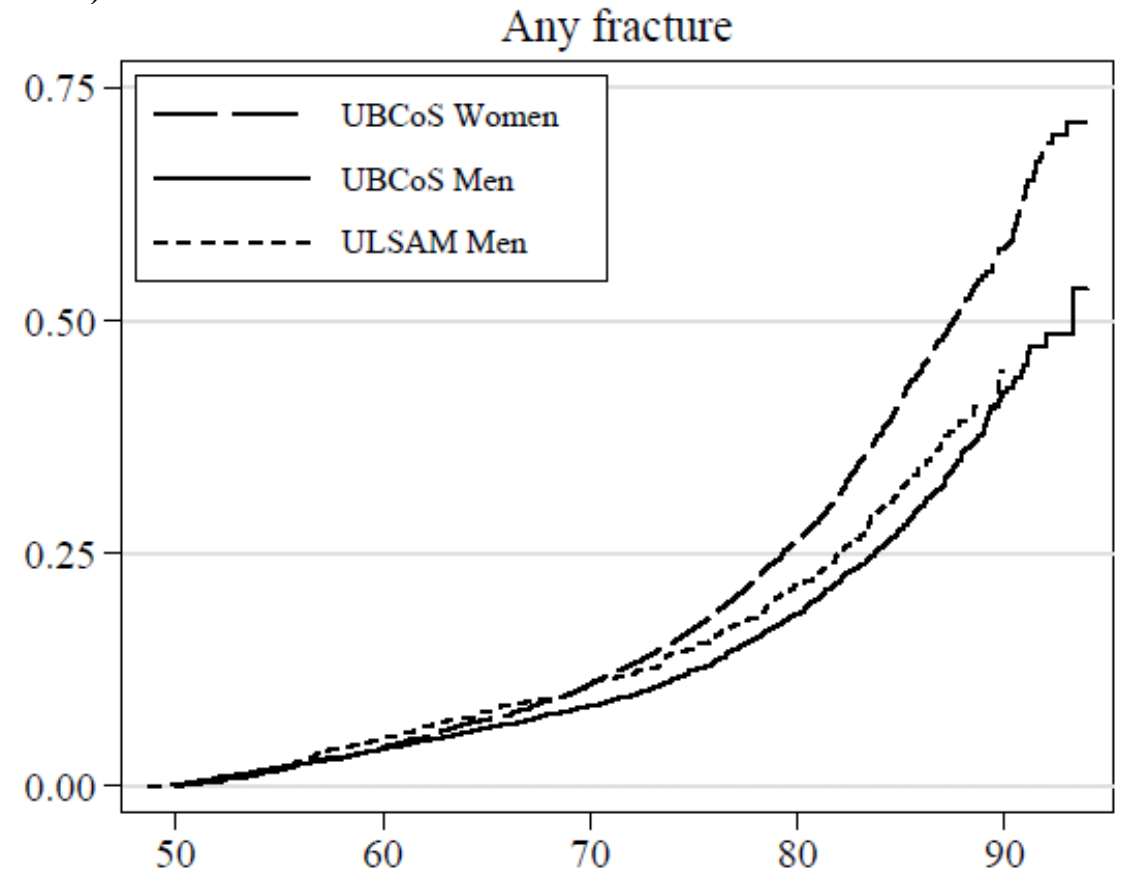

Hip fracture

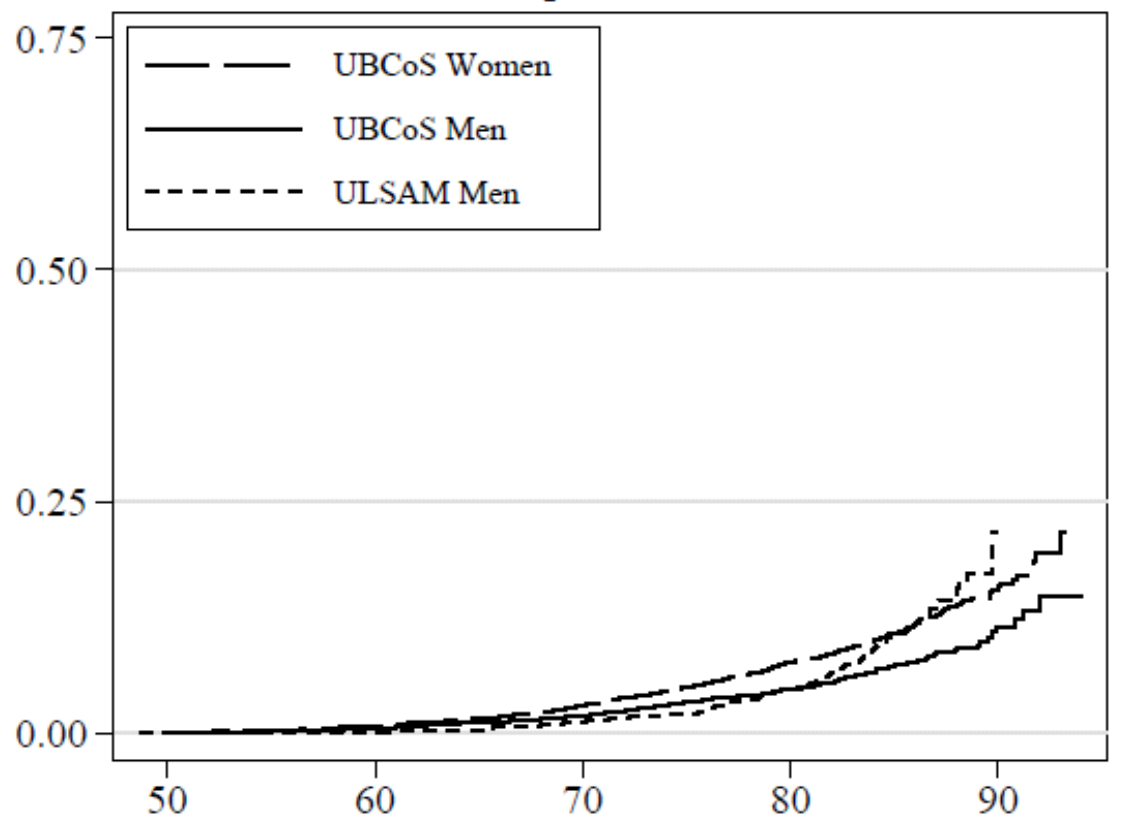

Age, years 
Supplemental Figure 3. Comparison of cumulative incidence curves for total mortality and hip fracture and the Kaplan-Meier failure curve for hip fracture in birth weight categories among women (top panel) and men (bottom panel) in the Uppsala Birth Cohort Study (born 1915-29).
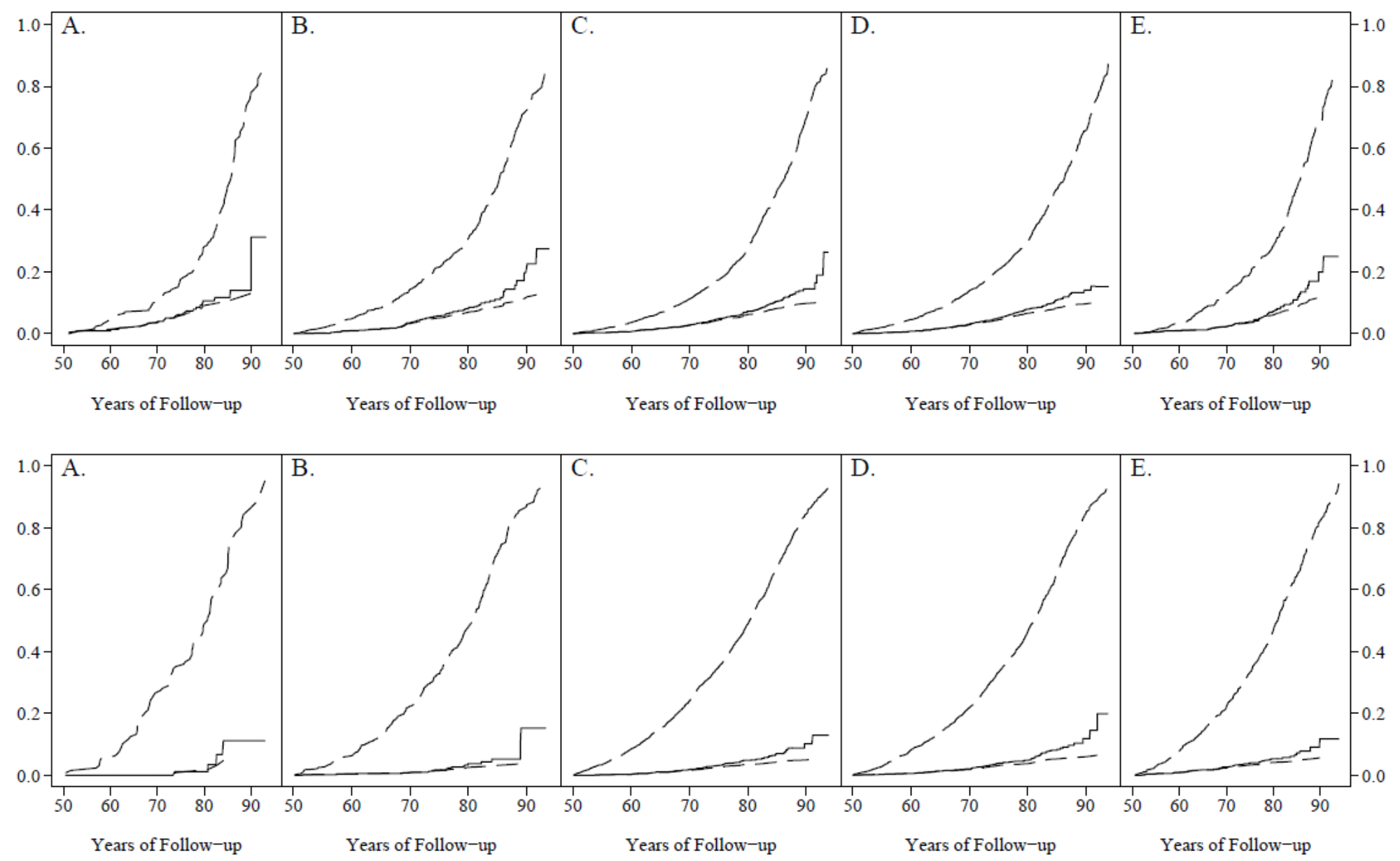

The figures indicate that the overestimation of hip fracture incidence by the Kaplan-Meier failure estimate is small and does not differ much by the categories of birth weight and that an approximation to survival methods is acceptable.

Solid line: Kaplan-Meier failure estimate for hip fracture. Short-dashed line: Cumulative incidence curve for hip fracture. Long-dashed line: cumulative incidence for mortality. Birth weight categories A: $<2.5 \mathrm{~kg}, \mathrm{~B}: 2.5-2.9 \mathrm{~kg}, \mathrm{C}: 3.0-3.4 \mathrm{~kg}, \mathrm{D}: 3.5-3.9 \mathrm{~kg}, \mathrm{E}: \geq 4.0 \mathrm{~kg}$. 
Supplemental Table 1. Birth weight and risk of any fracture and hip fracture before and after age 70 years in women of the Uppsala Birth Cohort Study (born 1915-29)

\begin{tabular}{|c|c|c|c|c|c|c|}
\hline & \multicolumn{6}{|c|}{ Birth weight (kg) } \\
\hline & $<2.5$ & $2.5-2.9$ & 3.0-3.4 & $3.5-3.9$ & $\geq 4.0$ & Continuous \\
\hline & \multicolumn{6}{|c|}{ Any fracture } \\
\hline Women $<70$ years & & & & & & \\
\hline $\mathrm{N}$ cases & 22 & 84 & 225 & 147 & 61 & 539 \\
\hline Person-years at risk & 14498 & 51500 & 141806 & 112115 & 38639 & 358559 \\
\hline Rate $(95 \% \mathrm{CI})$ & 1.5 & 1.6 & 1.6 & 1.3 & 1.6 & 1.5 \\
\hline HR $(95 \% \mathrm{CI})$, unadjusted & $0.95(0.61,1.48)$ & $1.04(0.81,1.34)$ & 1.00 (reference) & $0.83(0.68,1.02)$ & $1.00(0.76,1.33)$ & $0.92(0.78,1.09)$ \\
\hline HR $(95 \%$ CI $)$, adjusted $^{a}$ & $0.95(0.61,1.47)$ & $1.04(0.81,1.34)$ & 1.00 (reference) & $0.83(0.68,1.03)$ & $1.01(0.76,1.34)$ & $0.93(0.78,1.10)$ \\
\hline \multicolumn{7}{|l|}{ Women $\geq 70$ years } \\
\hline $\mathrm{N}$ cases & 53 & 164 & 468 & 380 & 142 & 1207 \\
\hline Person-years at risk & 1840 & 6263 & 18706 & 14462 & 4928 & 46198 \\
\hline Rate $(95 \% \mathrm{CI})$ & 28.8 & 26.2 & 25.0 & 26.3 & 28.8 & 26.1 \\
\hline HR $(95 \% \mathrm{CI})$, unadjusted & $1.23(0.93,1.63)$ & $1.08(0.90,1.29)$ & 1.00 (reference) & $1.05(0.92,1.21)$ & $1.17(0.97,1.41)$ & $1.01(0.90,1.13)$ \\
\hline HR $(95 \%$ CI $)$, adjusted $^{a}$ & $1.23(0.93,1.63)$ & $1.08(0.90,1.28)$ & 1.00 (reference) & $1.06(0.93,1.21)$ & $1.18(0.98,1.43)$ & $1.02(0.91,1.14)$ \\
\hline & \multicolumn{6}{|c|}{ Hip fracture } \\
\hline \multicolumn{7}{|l|}{ Women $<70$ years } \\
\hline $\mathrm{N}$ cases & 7 & 24 & 55 & 47 & 12 & 145 \\
\hline Person-years at risk & 14602 & 51990 & 143100 & 113033 & 39066 & 361790 \\
\hline Rate $(95 \% \mathrm{CI})$ & 0.48 & 0.46 & 0.38 & 0.42 & 0.31 & 0.40 \\
\hline HR $(95 \% \mathrm{CI})$, unadjusted & $1.25(0.57,2.74)$ & $1.22(0.75,1.97)$ & 1.00 (reference) & $1.10(0.74,1.62)$ & $0.80(0.43,1.50)$ & $0.81(0.59,1.12)$ \\
\hline HR (95\% CI), adjusted ${ }^{a}$ & $1.24(0.57,2.73)$ & $1.22(0.76,1.98)$ & 1.00 (reference) & $1.10(0.75,1.63)$ & $0.81(0.43,1.52)$ & $0.82(0.59,1.13)$ \\
\hline \multicolumn{7}{|l|}{ Women $\geq 70$ years } \\
\hline $\mathrm{N}$ cases & 15 & 47 & 120 & 90 & 41 & 313 \\
\hline Person-years at risk & 2121 & 7459 & 22197 & 16801 & 5940 & 54517 \\
\hline Rate $(95 \% \mathrm{CI})$ & 7.1 & 6.3 & 5.4 & 5.4 & 6.9 & 5.7 \\
\hline HR $(95 \% \mathrm{CI})$, unadjusted & $1.37(0.80,2.34)$ & $1.19(0.85,1.67)$ & 1.00 (reference) & $0.99(0.75,1.30)$ & $1.29(0.91,1.84)$ & $1.00(0.80,1.25)$ \\
\hline HR $(95 \%$ CI $)$, adjusted $^{a}$ & $1.35(0.79,2.32)$ & $1.18(0.84,1.66)$ & 1.00 (reference) & $1.00(0.76,1.32)$ & $1.36(0.95,1.94)$ & $1.03(0.82,1.30)$ \\
\hline
\end{tabular}


Supplemental Table 2. Birth weight and risk of any fracture and hip fracture before and after age 70 years in men of the Uppsala Birth Cohort Study (born 1915-29)

\begin{tabular}{|c|c|c|c|c|c|c|}
\hline & \multicolumn{6}{|c|}{ Birth weight (kg) } \\
\hline & $<2.5$ & 2.5-2.9 & 3.0-3.4 & 3.5-3.9 & $\geq 4.0$ & Continuous \\
\hline & \multicolumn{6}{|c|}{ Any fracture } \\
\hline Men $<70$ years & & & & & & \\
\hline $\mathrm{N}$ cases & 10 & 39 & 138 & 172 & 79 & 438 \\
\hline Person-years at risk & 8689 & 37875 & 131299 & 138172 & 64397 & 380431 \\
\hline Rate $(95 \% \mathrm{CI})$ & 1.2 & 1.0 & 1.0 & 1.2 & 1.2 & 1.2 \\
\hline HR $(95 \% \mathrm{CI})$, unadjusted & $1.10(0.58,2.09)$ & $0.97(0.68,1.38)$ & 1.00 (reference) & $1.18(0.94,1.48)$ & $1.16(0.88,1.54)$ & $1.11(0.92,1.34)$ \\
\hline HR $(95 \%$ CI $)$, adjusted $^{a}$ & $1.10(0.58,2.10)$ & $0.95(0.67,1.36)$ & 1.00 (reference) & $1.19(0.95,1.48)$ & $1.18(0.89,1.55)$ & $1.12(0.93,1.35)$ \\
\hline \multicolumn{7}{|l|}{ Men $\geq 70$ years } \\
\hline $\mathrm{N}$ cases & 19 & 60 & 194 & 242 & 97 & 612 \\
\hline Person-years at risk & 877 & 4231 & 14240 & 15391 & 7079 & 41818 \\
\hline Rate $(95 \% \mathrm{CI})$ & 21.7 & 14.2 & 13.6 & 15.7 & 13.7 & 14.6 \\
\hline HR $(95 \% \mathrm{CI})$, unadjusted & $1.62(1.01,2.59)$ & $1.06(0.79,1.42)$ & 1.00 (reference) & $1.16(0.96,1.40)$ & $0.99(0.77,1.26)$ & $0.98(0.84,1.15)$ \\
\hline HR $(95 \%$ CI $)$, adjusted $^{\mathrm{a}}$ & $1.62(1.01,2.59)$ & $1.06(0.79,1.41)$ & 1.00 (reference) & $1.17(0.96,1.41)$ & $1.00(0.78,1.28)$ & $0.99(0.84,1.16)$ \\
\hline
\end{tabular}

\section{Men $<70$ years}

$\mathrm{N}$ cases

Person-years at risk

Rate $(95 \% \mathrm{CI})$

HR $(95 \% \mathrm{CI})$, unadjusted

HR $(95 \% \mathrm{CI})$, adjusted ${ }^{\mathrm{a}}$

\section{Men $\geq 70$ years}

$\mathrm{N}$ cases

Person-years at risk

Rate $(95 \% \mathrm{CI})$

HR $(95 \% \mathrm{CI})$, unadjusted

HR (95\% CI), adjusted ${ }^{\mathrm{a}}$

$\begin{array}{rr}0 & 4 \\ 8799 & 38129 \\ - & 0.10 \\ - & 0.44(0.16,1.25)\end{array}$

$0.44(0.15,1.24)$

132286

0.23

1.00 (reference)

1.00 (reference)

\section{fracture}

Adjusted model was adjusted for socioeconomic status at birth. 
Supplemental Table 3. HR (95\% CI) of any fracture and hip fracture per unit increase of birth length, gestational age and birth weight standardized to gestational age in singleton women and men of the UBCoS, born 1915-29.

\begin{tabular}{|c|c|c|c|}
\hline & Total & Women & Men \\
\hline & $\mathrm{HR}(95 \% \mathrm{CI})$ & $\mathrm{HR}(95 \% \mathrm{CI})$ & HR $(95 \% \mathrm{CI})$ \\
\hline \multicolumn{4}{|l|}{ Any fracture } \\
\hline Birth length $(\mathrm{cm})$, unadjusted & $0.98(0.96,0.99)$ & $0.99(0.97,1.01)$ & $0.99(0.96,1.01)$ \\
\hline Birth length $(\mathrm{cm})$, adjusted ${ }^{\mathrm{a}}$ & $0.99(0.98,1.01)$ & $1.00(0.97,1.02)$ & $0.99(0.96,1.02)$ \\
\hline Gestational age (weeks), unadjusted & $0.99(0.98,1.01)$ & $1.00(0.97,1.02)$ & $0.99(0.96,1.02)$ \\
\hline Gestational age (weeks), adjusted ${ }^{a}$ & $0.99(0.98,1.01)$ & $1.00(0.98,1.02)$ & $0.99(0.96,1.02)$ \\
\hline $\begin{array}{l}\text { Birth weight standardized to gestational } \\
\text { age, unadjusted }\end{array}$ & $1.02(0.98,1.06)$ & $1.00(0.95,1.05)$ & $1.04(0.98,1.11)$ \\
\hline $\begin{array}{l}\text { Birth weight standardized to gestational } \\
\text { age, adjusted }\end{array}$ & $1.03(0.99,1.07)$ & $1.01(0.96,1.06)$ & $1.05(0.99,1.12)$ \\
\hline \multicolumn{4}{|l|}{ Hip fracture } \\
\hline Birth length $(\mathrm{cm})$, unadjusted & $1.00(0.97,1.03)$ & $1.01(0.97,1.05)$ & $1.03(0.97,1.08)$ \\
\hline Birth length $(\mathrm{cm})$, adjusted ${ }^{a}$ & $0.99(0.96,1.03)$ & $0.98(0.94,1.03)$ & $1.01(0.95,1.08)$ \\
\hline Gestational age (weeks), unadjusted & $0.99(0.96,1.03)$ & $0.99(0.95,1.04)$ & $0.99(0.93,1.05)$ \\
\hline Gestational age (weeks), adjusted ${ }^{\mathrm{a}}$ & $1.01(0.97,1.04)$ & $1.00(0.95,1.05)$ & $1.02(0.96,1.09)$ \\
\hline $\begin{array}{l}\text { Birth weight standardized to gestational } \\
\text { age, unadjusted }\end{array}$ & $1.04(0.96,1.12)$ & $0.98(0.89,1.07)$ & $1.10(0.96,1.26)$ \\
\hline $\begin{array}{l}\text { Birth weight standardized to gestational } \\
\text { age, adjusted }^{\text {a }}\end{array}$ & $1.04(0.96,1.13)$ & $1.01(0.92,1.12)$ & $1.11(0.97,1.27)$ \\
\hline
\end{tabular}

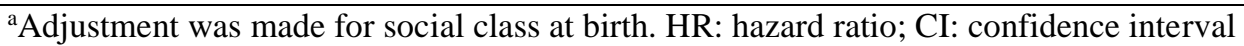

